\title{
The Neuropsychology of Cocaine Addiction: Recent Cocaine Use Masks Impairment
}

\author{
Patricia A Woicik*,', Scott J Moeller², Nelly Alia-Klein', Thomas Maloney', Tanya M Lukasik', Olga Yeliosof', \\ Gene-Jack Wang', Nora D Volkow ${ }^{3}$ and Rita Z Goldstein' \\ 'Brookhaven National Laboratory, Medical Department, Upton, NY, USA; 'Department of Psychology, University of Michigan, Ann Arbor, MI, \\ USA; ${ }^{3}$ National Institute on Drug Abuse, Bethesda, MD, USA
}

\begin{abstract}
Individuals with current cocaine use disorders (CUD) form a heterogeneous group, making sensitive neuropsychological (NP) comparisons with healthy individuals difficult. The current study examined the effects on NP functioning of four factors that commonly vary among CUD: urine status for cocaine (positive vs negative on study day), cigarette smoking, alcohol consumption, and dysphoria. Sixty-four cocaine abusers were matched to healthy comparison subjects on gender and race; the groups also did not differ in measures of general intellectual functioning. All subjects were administered an extensive NP battery measuring attention, executive function, memory, facial and emotion recognition, and motor function. Compared with healthy control subjects, CUD exhibited performance deficits on tasks of attention, executive function, and verbal memory (within one standard deviation of controls). Although CUD with positive urine status, who had higher frequency and more recent cocaine use, reported greater symptoms of dysphoria, these cognitive deficits were most pronounced in the CUD with negative urine status. Cigarette smoking, frequency of alcohol consumption, and dysphoria did not alter these results. The current findings replicate a previously reported statistically significant, but relatively mild NP impairment in CUD as compared with matched healthy control individuals and further suggest that frequent/recent cocaine may mask underlying cognitive (but not mood) disturbances. These results call for development of pharmacological agents targeted to enhance cognition, without negatively impacting mood in individuals addicted to cocaine.

Neuropsychopharmacology (2009) 34, I I 2-I I22; doi: I 0.1038/npp.2008.60; published online 2I May 2008
\end{abstract}

Keywords: cocaine addiction; neuropsychological function; alcohol; dysphoria; cigarette smoking; urine status

\section{INTRODUCTION}

Inconsistent results characterize studies of neuropsychological (NP) functioning in drug addicted individuals (Rogers and Robbins, 2001; Goldstein et al, 2004; Jovanovski et al, 2005). For example, comparing cocaine-addicted individuals with healthy control subjects on tasks of attention, executive function, and memory, several studies have reported severe deficits (Ardila et al, 1991; Gillen et al, 1998), while other studies reported no deficits on similar NP tasks (O'Malley et al, 1992; Hoff et al, 1996). In a recent factor-analytic study, our group reported statistically significant, but mild, deficits (ie, $<1$ SD below a control group mean) in verbal knowledge, visual, and verbal memory, and attention/executive functioning in 42 cocaine abusers and 40 alcohol-dependent individuals as compared

*Correspondence: Dr PA Woicik, Brookhaven National Laboratory, Medical Department, PO Box 5000, Upton, NY I 1973-5000, USA, Tel: + | 63 I 344 4472, Fax: + | 63| 344 5260,

E-mail: pwoicik@bnl.gov or Dr Rita Z Goldstein, Tel: + | 631344 2657, Fax: + I 631344 5260, E-mail: rgoldstein@bnl.gov

Received 18 December 2007; revised II March 2008; accepted 12 March 2008 with 72 control subjects (Goldstein et al, 2004). The main goal aim of the current study was to test the reliability of our previous results in a larger sample of individuals with cocaine use disorders (CUD). In addition, we aimed to test the effects of four factors that commonly vary within cocaine-addicted groups, namely urine status for cocaine, history of cigarette smoking and alcohol consumption, and dysphoric symptoms (Budney et al, 1993; Rusted et al, 1994, 1995; Di Sclafani et al, 2002; Richter et al, 2002; Poling et al, 2007). These factors may influence NP performance in drug abusers and possibly account for the inconsistencies in this literature.

\section{Drug Urine Status as a Measure of Abstinence/ Withdrawal Symptoms, Including Dysphoria}

Previous research suggests that NP function varies with the length of abstinence or withdrawal severity in CUD. For example, set shifting, a core executive function, is impaired when tested 2-4 weeks after last drug use in CUD (Ardila et al, 1991; Berry et al, 1993); this impairment is not evident at shorter abstinence periods (within $72 \mathrm{~h}$ of last drug use) (Berry et al, 1993). Since screening urine for drugs of abuse 
is common in clinical practice (eg, to assess adherence to treatment goals), we examined whether NP performance in CUD differs as a function of this objectively measured index of abstinence. In addition, we examined the extent to which dysphoric symptoms affect NP function, since depression/ dysphoria is a common psychostimulant withdrawal symptom (Association, 2000). Depression/dysphoria is also associated with more severe dependence (Schuckit et al, 1999; Sofuoglu et al, 2003), exacerbating NP deficits in drug-abusing (Di Sclafani et al, 2002) and non-drug abusing (Fossati et al, 2002) populations.

\section{Nicotine and Alcohol Use}

Cocaine abusers are more likely to smoke cigarettes compared with healthy control subjects; moreover, the frequency of cigarette smoking is positively related to their chronic use of cocaine (Budney et al, 1993; Roll et al, 1996). However, although nicotine has been shown to improve attention and memory in cigarette smokers (Rusted et al, 1994, 1995; Warburton et al, 2001), its effects on cognition in CUD have not been extensively explored. Concurrent use of alcohol is also common among CUD. It is associated with more severe cocaine dependence (Higgins et al, 1994) and higher reports of adverse cocaine use consequences (Heil et al, 2001). NP deficits, such as attention, memory, and executive and motor functions, are commonly impaired with chronic alcohol use (Parsons and Nixon, 1993; Beatty et al, 2000; Ikeda et al, 2003); however, it is unclear how alcohol is related to NP deficits in cocaine addiction. Therefore, the current study examined whether cigarette smoking and alcohol use are differentially associated with NP performance in CUD.

\section{MATERIALS AND METHODS}

\section{Participants and Procedure}

All protocols within the current study were approved by the ethical committee of the institutional review board and therefore were conducted in accordance with the ethical standards presented in the 1964 Declaration of Helsinki Principles.

Eighty-four cocaine-addicted subjects who consented for participation in 16 of our neuroimaging protocols at Brookhaven National Laboratory (these protocols use positron emission tomography and/or magnetic resonance imaging; for additional information on imaging procedures we refer the reader to other published works, Wang et al, 2001, 2004; Goldstein et al, 2007a, b, c) completed the NP battery. Of these, we selected 64 subjects based on their history of cocaine use, age (18-55 years), and the ability to match them to control subjects on gender and race (one cocaine-addicted subject was matched on gender but not race). This process yielded 128 subjects for the current analysis (64 CUD and 64 control). Cocaine abusers met DSM-IV diagnostic criteria for history of cocaine dependence or abuse (reporting cocaine as their preferred drug and with primary use of cocaine by smoked route). Comparison subjects were 64 healthy individuals with no history of drug addiction. Subjects were initially screened by phone and then evaluated by a neurologist to ensure that they met inclusion and exclusion criteria. Exclusion criteria for all subjects were history of head trauma with loss of consciousness greater than $30 \mathrm{~min}$ and/or a history of neurological, cardiovascular, endocrinological, and/or current psychiatric disorders (apart from cocaine and alcohol abuse or dependence for the cocaine group or nicotine dependence for the control and cocaine groups). Five cocaine subjects who reported cocaine as their preferred drug and who met DSM-IV criteria for cocaine abuse/ dependence also met criteria for current alcohol dependence. No subject was taking medications at the time of the study.

Participants were administered the NP assessment either on a separate random day or as a separate module that was independent of the imaging procedures (completion of the study ranged from 2-5 days depending on the protocol). On the morning of each study day, a triage urine panel for drugs of abuse (Biopsych) was used to test for presence of cocaine and its metabolites in all study subjects. A positive result indicated cocaine use within $72 \mathrm{~h}$ (the maximal resolution of the urine test) of $\mathrm{NP}$ testing (CUD,$+ N=43)$, and a negative result indicated longer term abstinence (CUD-, $N=21$ ). With the exception of cocaine in CUD, a positive result for any other drugs (ie, marijuana, opiates, benzodiazepines, phencyclidine, amphetamine/methamphetamine, barbiturates) was exclusionary. All other information, including history of cocaine use, alcohol consumption (for cocaine abusers only), cigarette smoking, and dysphoria (depressive symptoms in the past two weeks as assessed with Beck's Depression Inventory II (BDI)) (Beck et al, 1996) was collected via self-report.

\section{NP Battery}

The NP battery (see Table 2) was composed of wellvalidated NP measures of attention and executive function, memory, facial and emotion recognition, and motor function (Lezak, 1995). Also included in the battery were measures of verbal and non-verbal intelligence estimated with age-corrected scores from the reading subscale of the Wide Range Achievement Test 3 (WRAT 3) (Wilkinson, 1993) and matrix reasoning subscale of the Wechsler Abbreviated Scale of Intelligence III, respectively. Although the WRAT 3 reading subtest is considered an achievement test, it is also used as an estimate of verbal IQ and premorbid intelligence and is highly related to other wordbased IQ indices such as the National Adult Reading Test $(r=0.8)$ and verbal IQ indices from the Wechsler intelligence scales for children and adults $(r=0.7)$. It is also a better verbal IQ estimate in lower SES and minority populations (Strauss et al. 2006). Tasks measuring attention/executive function were the (1) Controlled Oral Word Association Task (Benton, 1968) assessing flexibility of verbal thought processes and the ability to update working memory (number of correct words produced for phonemic (2 categories - letters ' $F$ ' and ' $S$ ') and semantic categories (2 categories _ 'animals' and 'fruits and vegetables'), 1 min per category); sensitivity and specificity for both indices are reliable in discriminating controls from those with impaired frontal function (sensitivity of 88 and $100 \%$ has been reported for phonemic and semantic categories, respectively) (Lezak, 1995); (2) digit span (standardized scores 
based on the sum of raw scores for both forward and backward tests) and letter-number sequencing subtests from the Wechsler Adult Intelligence Scale III; Wechsler, 1997) assessing attentional capacity and verbal working memory; both subtests have adequate sensitivity and specificity (Lezak, 1995); (3) Symbol Digit Modalities Test (Smith, 1982) assessing attentional capacity (written; number of correct responses in $90 \mathrm{~s}$; possessing ample sensitivity (approximately 80\%) in detecting brain injury and learning disorders) (Lezak, 1995); (4) Trail Making Test (Reitan, 1955) assessing visual motor tracking, cognitive flexibility, and planning (trails A and B are very sensitive to cognitive decline and differentiate controls from both mild and severe head trauma patients; sensitivity of 77 and $79 \%$ has been reported for trails $\mathrm{A}$ and $\mathrm{B}$, respectively) (O’Donnell et al, 1984; Lezak, 1995); (5) Mazes subtest from the Wechsler Intelligence Scale for Children III (Wechsler, 1987) assessing planning and sustained attention (this subtest is a 'satisfactory substitute for longer adult tests such as the Porteus mazes' in assessing executive functioning for most clinical purposes; (we used scaled scores based on norms for the highest (16 years) age) (Lezak, 1995); (6) Wisconsin Card Sort Test 3 (Berg, 1948) computerized version (Heaton, 1999) assessing set shifting and planning (specificity for the Wisconsin Card Sort Test is reported to be low, however it is very sensitive to the effects of frontal damage); and the (7) Color-Word Stroop Task (Golden, 1978), an index of directed attention and cognitive flexibility (the Color-Word Stroop is sensitive to both mild and severe frontal lobe impairment, differentiating those with learning disabilities or Attention Deficit Hyperactivity disorder from controls (eg, sensitivity, 89\%)) (Homack and Riccio, 2004; Lezak, 1995). Two newly developed tasks of executive function were also included in this NP battery, and although more studies are needed to test their validity, recent reports have provided evidence for their utility in distinguishing specific executive domains: (8) the Attention Network Test (Fan et al, 2002) using reaction time to measure alerting (response readiness), orientating (scanning/selection), and executive control (conflict resolution); and the (2) Iowa Gambling Task (Bechara et al, 1994) measuring advantageous decision making. Verbal learning and memory was assessed by the (10) California Verbal Learning Task II (CVLT) (Delis et al, 2000) involving list learning, recall, recognition, semantic and serial learning strategies, and the degree of vulnerability to cognitive interference (performance on the CVLT effectively discriminates patients with left $v s$ right temporal lobe dysfunction from control subjects) (Lezak, 1995). Emotion and facial recognition was measured with the (11) Ekman Faces test (Ekman, 1993) measuring recognition of six different emotions (sensitivity and specificity for the Ekman tests are good (eg, 94\% sensitivity and 100\% specificity in discriminating patients with frontotemporal dysfunction from healthy controls)) (Diehl-Schmid et al, 2007) and (12) Benton Facial Recognition Test (corrected long form scores) (Benton, 1990) that measured the ability to match faces. Motor function was measured by the (13) Timed Gait test (Robertson et al, 2006) (average time to walk a 12-foot floor-length back and forth for a total of three trials), with fine motor coordination assessed by the (14) Finger Tapping Test (the mean of the closest three out of five trials for each hand) (Reitan, 1985), a simple test of motor speed and motor control (tests of its sensitivity/specificity indicates that this test is a poor screening instrument but is useful as a diagnostic supplement) (Lezak, 1995), and (15) Grooved Pegboard Test (Ruff and Parker, 1993), a motor task including complex coordination (there is adequate sensitivity for this test in classifying brain damaged patients) (Lezak, 1995). All tests were presented in the same fixed order for all subjects. The complete battery was administered in a quiet room with all but three subjects completing the NP battery in one sitting. To minimize fatigue, subjects were encouraged to take a short break toward the middle of the battery. Cigarette smokers were asked to refrain from smoking throughout the NP session and the short break; nevertheless, two subjects smoked a partial cigarette during the short break. In addition, nine smokers reported smoking a cigarette just prior to the NP assessment.

\section{Statistical Analyses}

$\chi^{2}$-Tests (for categorical variables) or analyses of variance (for continuous variables, omnibus results followed with Tukey's post-hoc comparisons) were conducted on all demographic variables and NP tests. The potential impact of all demographic variables that differed between the study groups (Table 1) was examined as follows: if significantly correlated with the dependent variables (NP measures), the demographic variable was entered as a covariate in an analysis of covariance (Tabachnick and Fidel, 1983). The effect of dysphoria on cognitive function was examined with correlations between BDI scores and all NP tests for each study group separately, across all CUD, and across all study subjects. Since BDI scores (and two of the alcohol consumption measures) did not follow a normal distribution, Spearman's $\rho$ correlations were computed. For cigarette smoking, we conducted parametric correlations between frequency of current cigarette smoking and all NP measures for the current smokers only (again, for each study group separately, across all CUD, and across all study subjects). Finally, for both CUD subgroups (separately and combined), we also inspected Pearson productmoment correlations between all NP measures with selected cocaine and alcohol use variables. Analyses of covariance were also conducted for the NP measures that both significantly differed between the groups and were associated with any of these other variables (dysphoria, cigarette smoking, alcohol use, or cocaine use). Across all betweengroup analyses, $p<0.05$ was considered significant; to protect against type-I error, a Bonferroni correction was applied to all correlation analyses involving NP measures $(0.05 / 15=0.01)$.

\section{RESULTS}

\section{Sample Demographics and Characteristics}

There were no differences between the study groups in distributions of gender, race, English as first language, handedness, and in estimates of verbal and non-verbal intelligence (scores on these measures followed a normal distribution with no outliers (no cut-off criteria were 
Table I Demographics, General Intellectual Functioning, Dysphoria, and Self-Reported Alcohol and Drug Use

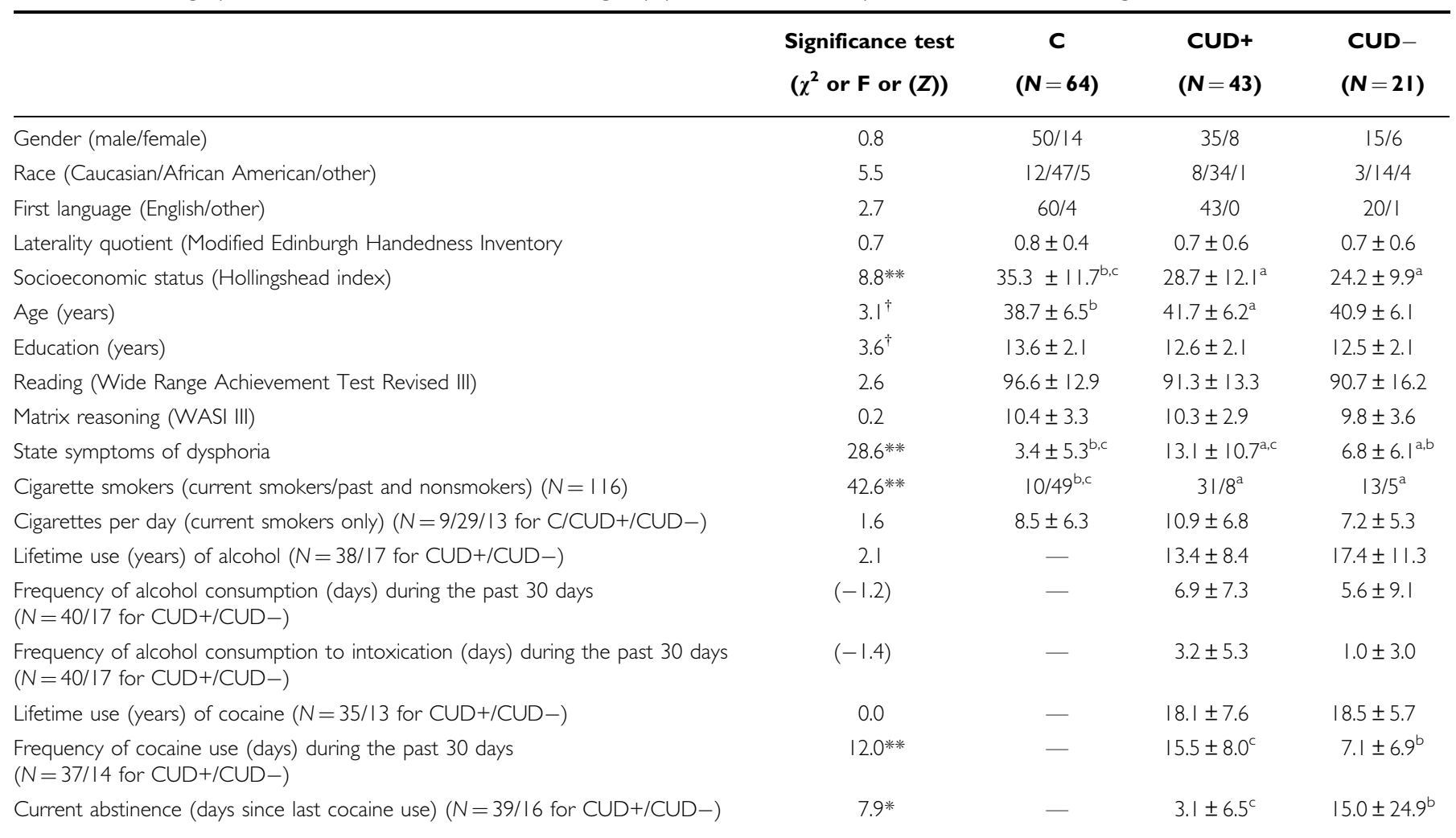

Note: C, control subjects; CUD+, participants testing positive for cocaine on the day of NP testing; CUD-, participants testing negative for cocaine on the day of NP testing; all values under group categories are either distributions or the mean \pm the standard deviation;

${ }^{*} *{ }^{*} p<0.00$ I, ${ }^{*} p<0.01,{ }^{\dagger} p<0.05$. Post hoc tests were not significant for education.

aMean value significantly differs from that of the control group.

bMean value significantly differs from that of the cocaine positive group.

'Mean value significantly differs from that of the cocaine negative group.

imposed). Mean socioeconomic status, age, and education differed between the groups. These group differences were accounted for as described in Statistical Analyses. There were no group differences in time to complete the entire NP Battery. Means and SDs for these variables are presented in Tables 1 and 2.

As expected, the CUD + subgroup reported a shorter abstinence period and higher frequency of recent cocaine use than the CUD- subgroup (Table 1). Consistent with the effects of acute withdrawal on mood (Johanson et al, 1999; Dudish-Poulsen and Hatsukami, 2000), the CUD + also reported more dysphoria than both CUD - and controls (CUD + > CUD $->$ controls). The F-value for BDI (reported in Table 1) was computed using transformed BDI scores (ie, square root transformation) as raw BDI scores were non-normally distributed; however, to facilitate interpretation, means and SDs presented in the table are raw scores. Further, history of cigarette smoking was more frequent in both CUD subgroups as compared with that in control subjects. Consistent with prior reports (Budney et al, 1993; Roll et al, 1996), the complete CUD group showed a positive association between cocaine use and frequency of current cigarette smoking: the more frequent the recent cocaine use and the longer the lifetime use of cocaine, the higher the number of cigarettes smoked per day $(r=0.5$ and 0.4 , $p<0.05$, respectively). This effect was driven by the CUD + subgroup. Alcohol consumption did not differ among the cocaine subgroups (Mann-Whitney tests were conducted on two measures of alcohol use with skewed distributions (the number of days of alcohol consumption in the last 30 days and the number of days it was consumed to intoxication in the last 30 days). The $Z$-values yielded from these tests are presented in Table 1.), and was not associated with cocaine or nicotine use.

\section{Attention and Executive Function}

There were significant group main effects on four of the attention/executive function measures including: digit span, letter-number sequencing, Wisconsin Card Sort Test (percent correct), and the executive control index of the Attention Network Test (Table 2). Follow-up tests for these NP measures showed statistically significant differences between the controls and CUD- only. Although the CUD + outperformed the CUD-, while performing worse than controls on all of these measures, these differences for the CUD + subgroup did not reach the nominal statistical significance level.

Controlling for the potential demographic covariates (one at a time), the effect for digit span was no longer significant, 
Table 2 Means and SDs for all Neuropsychological Tests

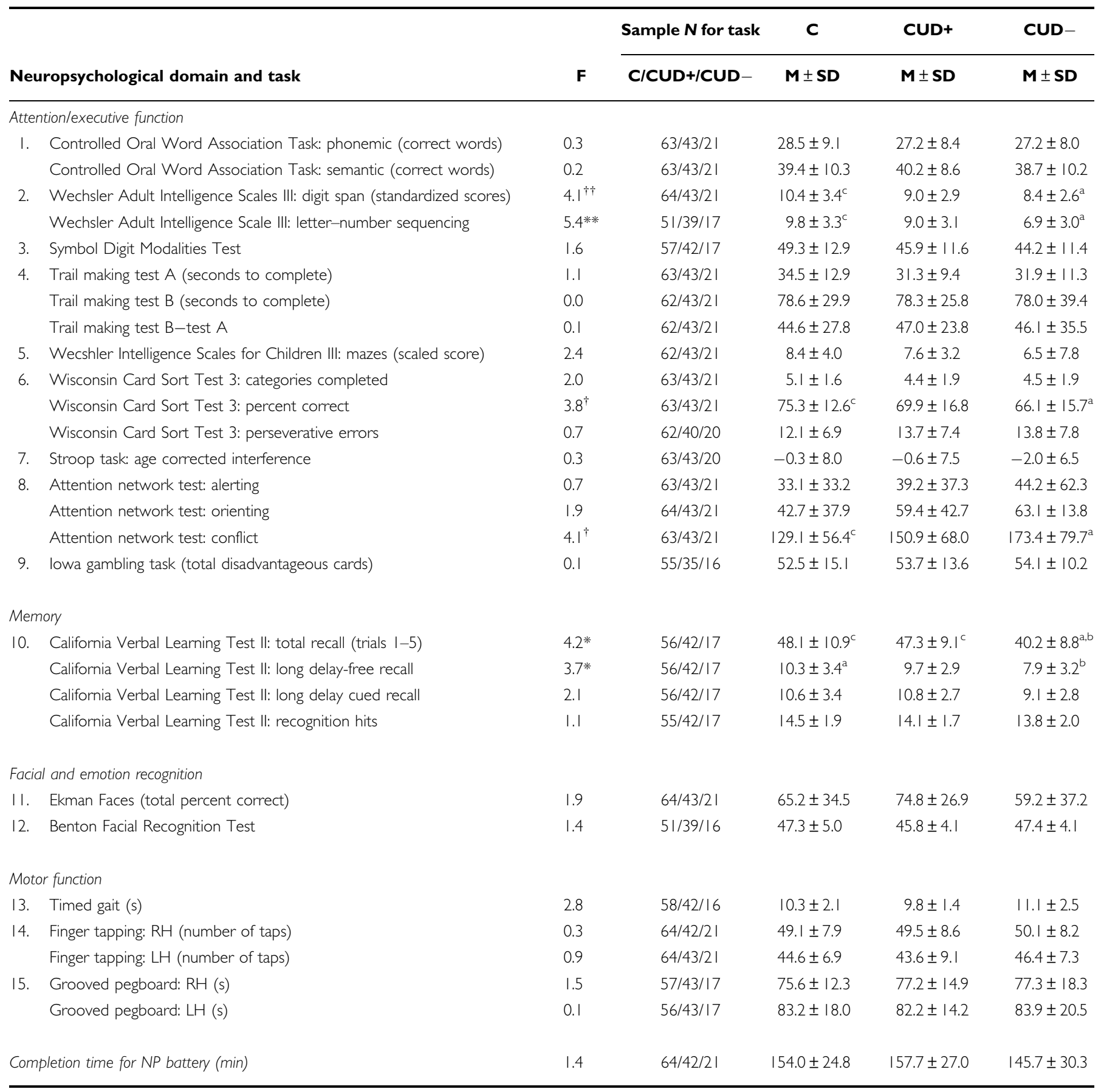

Note: N, number of subjects with complete data; C, control subjects; CUD+, participants testing positive for cocaine the day of NP testing; CUD-, participants testing negative for cocaine the day of NP testing;

${ }^{*} * 0<0.01,{ }^{*} p<0.05$. "Indicates significant effect in the ANOVA $(p<0.05)$, but reduced to a trend $(p<0.10)$ in ANCOVA; ${ }^{\dagger \dagger}$ indicates significant effect in the ANOVA $(p<0.05)$, but insignificant result in ANCOVA $(p<0.10)$.

a Mean value significantly differs from that of the control group.

bMean value significantly differs from that of the cocaine positive group.

'Mean value significantly differs from that of the cocaine negative group.

and the effects for Attention Network Test and Wisconsin Card Sort Test were reduced to trends $(\mathrm{F}(2,127)=2.5$, $p<0.09$ and $\mathrm{F}(2,127)=2.4, p<0.10$, respectively) (Figure 1; Supplementary Table 1). The effect for letter-number sequencing remained significant $[\mathrm{F}(2,107)=5.08, p<0.01]$.
There were no significant correlations between the attention/executive function NP measures and frequency of cigarette smoking in the current smokers (correlations ranged from 0.02 to 0.2 , all $p>0.07$ ). However, the number of days that alcohol was consumed (and consumed to 


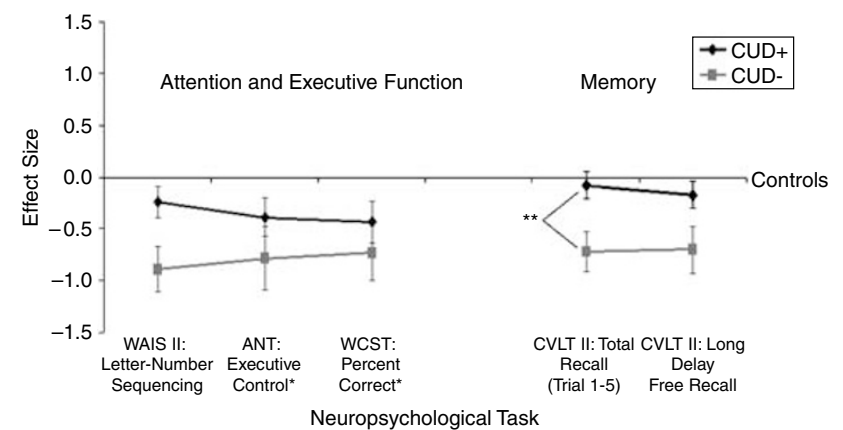

Figure I Neuropsychological performance of cocaine-addicted subjects as compared with control subjects. CUD+ and CUD- = cocaine subjects who tested positive or negative for cocaine, respectively. WAIS III = Wechsler Adult Intelligence Scale III; ANT= Attention Network Test; WCST Wisconsin Card Sort Test CVLTII=California Verbal Learning Test II; Z-scores were computed for all NP variables to present effect sizes for each cocaine subgroup as compared to control subjects whose mean score was converted to zero and standard deviation to I. All effect sizes for CUD - are significantly different from controls, $p<0.05$; error bars are the standard error mean; **CUD+ scores are significantly different from CUD-, $p<0.05$; * $<0.10$ in ANCOVA analysis.

intoxication) in the past 30 days was significantly related to poorer performance on the Symbol Digit Modalities Test for all CUD $(r=-0.4$ for both indices, $p<0.01)$. Current abstinence from cocaine, lifetime use of cocaine, and frequency of cocaine use did not correlate with any of the $\mathrm{NP}$ attention/executive function measures in the CUD subjects (complete group or subgroups).

There was a trend for symptoms of dysphoria to be associated with poorer performance on digit span $(r=-0.2)$ and letter-number sequencing $(r=-0.3)$ in the entire sample (all $p<0.01$ ) as driven by the control group $(p<0.05)$. A post hoc analysis of covariance controlling for dysphoric symptoms showed no impact on the significant group differences reported for letter-number sequencing (the NP measure that remained significantly different between the groups after accounting for other relevant covariates in Table 1) $(\mathrm{F}(2,107)=5.08, p<0.01)$.

\section{Memory Function}

There were significant group main effects on the CVLT measures of total recall and long-delay-free recall (Table 2; Figure 1). Follow-up tests showed that the healthy control subjects outperformed the CUD - in both measures. For total recall, the CUD + subgroup performed similarly to controls, outperforming the CUD- subgroup at a statistically significant level (Figure 1; Supplementary Information). There were no significant correlations between the demographic variables that differed between the study groups and the CVLT measures; analyses of covariance were therefore not performed. No significant associations were found between any of the CVLT measures with cigarette smoking, alcohol consumption, or the selected cocaine use variables for the complete sample or the selected subgroups as explained above.

Greater dysphoria was associated with less recognition hits on the CVLT in the CUD - subgroup $(r=-0.4$, $p<0.01$ ).

\section{Emotion and Facial Recognition and Simple and Complex Motor Function}

There were no significant differences between the groups on these selected tests. In addition, we found no significant associations between these tests with symptoms of dysphoria, cigarette smoking, alcohol, or cocaine use for the complete sample or selected subgroups.

\section{DISCUSSION}

\section{A Neuropsychological Profile of Cocaine Abuse}

We previously reported that compared with healthy control subjects, subjects with CUD exhibit statistically significant and generalized, but mild, cognitive impairment as measured with classical NP tasks (Goldstein et al, 2004). Our current findings (group main effects) in a larger sample of CUD and healthy control subjects replicate these previous results, pointing again to statistically mild impairments in attention/executive function and verbal memory. Together, results of both studies are consistent with a recent meta-analytic review indicating performance deficits in similar cognitive domains (ie, memory and executive function) in CUD (Jovanovski et al, 2005). The statistical modest extent of this NP impairment may be a contributing factor to the reluctance to define drug addiction as a disorder of the brain in the general public. Nevertheless, these deficits, although statistically mild, negatively affect treatment outcome/retention (see negative correlations between performances on the MicroCog Assessment of Cognitive Functioning and Wisconsin qCard Sort Test with the number of weeks in cognitivebehavioral treatment and program dropout rate) (Aharonovich et al, 2003, 2006) and may have pronounced consequences to daily functioning. Note that, as with all cross-sectional designs, our study cannot affirm whether these deficits have predated the development of drug addiction, predisposing vulnerable individuals to developing addiction, or whether these cognitive deficits are a consequence of drug use.

Our secondary goal was to inspect the potential impact on this NP profile of variables that frequently vary within addicted subgroups: urine status for cocaine as an abstinence/withdrawal index, cigarette smoking, alcohol use, and symptoms of dysphoria. Our results indicate a consistent trend for a more severe level of attention/executive and verbal memory impairment in the CUD - than the CUD + subgroup. However, these findings should be cautiously interpreted, as there was only one statistically significant difference between the CUD subgroups (on CVLT total recall; for all other NP measures, the significant difference was between CUD- and controls).

In general, the relatively better performance in the CUD + group could not be attributed to current cigarette smoking or alcohol use (that did not differ between the CUD subgroups) or dysphoria (that was higher in the CUD +). Consistent with the more frequent and recent cocaine use in the CUD + group, this pattern of results may be attributed to the neurocognitive enhancing effects of acute cocaine in CUD (Higgins et al, 1990; Johnson et al, 1998, 2005), discussed below. 
Impairment of Attention and Executive Function in Cocaine Abusers

The CUD- group exhibited impairments on the letternumber sequencing test with similar trends for the WCST and ANT. These tasks encompass attention/working memory, concept formation, and behavioral control, all functions that rely heavily on the prefrontal cortex (Miller and Cohen, 2001). Our current NP results are therefore consistent with numerous neuroimaging studies that report hypofrontality in abstinent CUD, while performing attention/executive function tasks (eg, Bolla et al, 2004; Goldstein et al, 2007a,b; Tomasi et al, 2007a), underscoring the importance of the prefrontal cortex in underlying the core addiction symptoms (Goldstein and Volkow, 2002).

A trend for deficits on the executive control subtest of the Attention Network Test (but not on alerting or orienting subtests) was observed in the CUD- subgroup (as compared with controls), a novel finding in the drug addiction literature; such specificity was previously reported only in patients with schizophrenia (Wang et al, 2005; Neuhaus et al, 2007). Performance on this particular subtest of the Attention Network Test is associated with the anterior cingulate cortex, and with left lateral prefrontal, primary, and supplementary motor areas as measured with functional magnetic resonance imaging and source analysis of an event related potential component (P300) latency (Fan et al, 2003, 2005, 2007). Interestingly, these brain regions have also been associated with abstinence, drug craving, and relapse (Sinha and $\mathrm{Li}, 2007$ ). It is therefore possible that this specific executive impairment in the CUD - subgroup is a manifestation of an underlying prefrontal brain dysfunction that may predispose individuals to impulsivity, drug use, and relapse even after extended periods of abstinence.

Note that despite the documented role for the prefrontal cortex in performance on the Iowa Gambling Task (IGT) (Bechara et al, 1994, 2001), and in contrast to previous functional neuroimaging studies in substance abusers (Bartzokis et al, 2000; Grant et al, 2000; Bolla et al, 2003), we found no significant differences between controls and the CUD subgroups in decision-making as measured with this task (including net scores (the percentage of disadvantageous cards selected from the total deck) for each of the five trials in the task). This negative result might be attributed to sample differences between the studies (eg, earlier studies have relied on smaller samples of CUD who were treatment-seeking or closely monitored), but also highlights the importance using novel/more targeted functional neuroimaging paradigms. Promising paradigms encompass cognitive-emotional processes that uniquely engage prefrontal corticolimbic brain areas as a function of drug addiction. For example, Goldstein et al (2007a,b), observed a relationship between reward sensitivity and frontolimbic brain function using a monetary reward task; Kaufman et al (2003 observed a relationship between behavioral inhibition and cingulate hypoactivity; and Tomasi et al observed relationships between both sustained attention (Tomasi et al, 2007a), working memory (Tomasi et $a l, 2007 \mathrm{~b}$ ), with prefrontal functional abnormalities using visuospatial attention and verbal memory (N-back) tasks.

\section{Memory Impairments in Cocaine Abusers with a Negative Urine Status: Withdrawal/Abstinence Effects}

Consistent with other reports (Pace-Schott et al, 2005), and with a previously suggested 'learning lag' in drug abusers (Verdejo-Garcia et al, 2007), our results revealed immediate verbal learning (CVLT total recall) and delayed verbal memory (CVLT delay-free recall) deficits that were most pronounced in the CUD- subgroup. These findings are noteworthy in light of recent evidence from animal research that points to modulation of memory function based on the cocaine withdrawal period; synaptic activity (long-term potentiation) was significantly compromised in the CA 1 region of the hippocampus in rats which had undergone a longer withdrawal period from cocaine (100 days) vs those with shorter periods of withdrawal (3 days) (Thompson et al, 2004). The notion that memory deficits are more pronounced with longer abstinence, an effect that until now was not reliably observed in humans, is clinically relevant. Indeed, it may explain why drug abusers in treatment often fail to use newly 'learned' strategies aimed to prevent relapse. However, we cannot rule out the possibility that CVLT total recall reflects attention/executive dysfunction rather than a primary learning/memory deficit. Therefore, this finding remains to be replicated using additional memory tasks (including non-verbal tasks).

\section{No Effects of Cocaine Abuse on Facial and Emotional Recognition}

Using Ekman task, no differences were found between the CUD and controls in recognition of facial emotional expression in the current study. This negative result contrasts with evidence of impaired fear recognition in recreational cocaine users (average use $=$ once per month) (Kemmis et al, 2007) and of similar difficulties as documented using additional emotional recognition tasks in current and abstinent abusers of other drugs (eg, 3,4methylenedioxy-N-methylamphetamine, opiates, alcohol) (Hoshi et al, 2004); (Kornreich et al, 2003; Townshend and Duka, 2003). A possible explanation for this difference may pertain to the inclusion criteria. For example, in the study by Kemmis, history of other drug dependence (eg, ecstasy, heroin, cannabis) was not exclusionary, whereas in our study it was; drugs other than cocaine may, therefore, drive impairments in emotion recognition. Therefore, it remains to be determined whether deficits in emotion recognition, particularly fear recognition, are associated with cocaine use.

\section{No Effects of Cocaine Abuse on Motor Function}

The current results suggest intact simple and complex motor function in cocaine abusers. These results contrast with findings in methamphetamine-addicted individuals in whom motor function was compromised (as measured with the grooved pegboard) compared with healthy control subjects and attributed to reductions in striatal dopamine transporter levels (Volkow et al, 2001). These differential results for cocaine $v s$ methamphetamine abusers may reflect the unique impact of these psychostimulants on dopaminergic, serotonergic or noradrenergic 
motor-output systems (Muller et al, 2003, 2007; Jones et al, 2007), possibly revealing more methamphetamineinduced neurotoxicity.

\section{Cigarette Smoking, Alcohol Consumption, and Dysphoria}

Consistent with previous research (Budney et al, 1993; Roll et al, 1996), we found that lifetime and recent cocaine abuse were associated with increased cigarette smoking. Both nicotine and cocaine influence reward-processing mechanisms (Pich et al, 1997) such that when used simultaneously, dopamine is increased in limbic brain areas (Gerasimov et al, 2000). In contrast to recent cocaine use, however, cigarette smoking was unrelated to NP function in the current study. These results are consistent with those of other studies that showed minimal or no effect of nicotine on certain cognitive tests (eg, logical reasoning) in drug abusers (Bell et al, 1999). Nevertheless, nicotine has been known to enhance cognition (verbal memory and attention) in healthy smokers (Jacobsen et al, 2005) and non-smokers (Kumari et al, 2003). Because in our study there was some variability in recency of cigarette smoking (11 subjects smoked a cigarette close to the NP assessment, see section NP Battery), our current results that pertain to cigarette smoking should be cautiously interpreted. Future studies incorporating objective measures of cigarette smoking history and severity (eg, breath $\mathrm{CO}$, or nicotine and cotinine in urine) and targeted test-retest designs (eg, assessment of NP function before and after cigarette smoking) are needed to test the reliability of these results. It should be noted, however, that our findings largely pertain to CUD-, which did not differ from CUD + in smoking history. Therefore, the main findings for CUD- cannot be fully explained by withdrawal from cigarette smoking.

The current results suggest a relationship between alcohol use frequency in CUD and specific attention/executive processes (ie information processing speed and sustained attention as indexed by the Symbol Digit Modalities Test; Lezak, 1995). Cocaine-addicted individuals often report use of alcohol to reduce the negative effects brought on by a cocaine binge (Magura and Rosenblum, 2000). However, this practice may be cognitively detrimental. This remains to be investigated in future studies.

Greater dysphoria was associated with worse performance on two attention/executive function measures, a finding that reached significance in the entire sample as driven by the healthy control subjects. This is consistent with studies in individuals with clinical depression where executive deficits, as associated with frontal lobe dysfunction, have been widely reported (Fossati et al, 2002). However, similar correlations with attention/executive function measures were not observed in the CUD subjects in the current study. Because the CUD + reported the highest levels of dysphoria, but evidenced less NP dysfunction than the CUD- group, our findings suggest that other factors, independent of dysphoric symptoms, may account for the cognitive dysfunction-characterizing CUD.

\section{Study Limitations and Future Research}

Limitations to the current study include (1) the reduced number of subjects in the CUD - as compared with the
CUD + subgroup, which may have underestimated differences between groups. However, our total CUD sample was larger than in previous NP studies and we controlled for key demographic factors, reducing the influence of unique sample error on our results; (2) cross-sectional ( $v s$ longitudinal) designs restrict interpretations about the effects on NP function of acute $v$ s longer term withdrawal; and (3) a wider extent of group differences may have been identified with newer/more tailored NP measures. For example, we reported that chronic cocaine abusers, especially CUD +, produce more words than control subjects on a newly developed Drug Fluency task; this result was absent when using the traditional phonemic or semantic fluency categories of the Controlled Oral Word Association Task, suggesting greater salience of or attention bias to drug related information in currently using addicted individuals (Goldstein et al, 2007a,b,c). Other novel behavioral measures have been used to successfully assess deficits in reflection impulsivity (the collection and assessment of information prior to decision making) in current and former amphetamine or opiate abusers (Clark et al, 2006). Together these studies reflect new directions in addiction NP research.

\section{CONCLUSIONS}

Consistent with previous studies, we report NP impairment in cocaine addiction that is modest but statistically discernible. These NP deficits encompassed attention/ executive function and verbal learning and memory, and could not be attributed to measures that frequently vary between healthy control and cocaine-addicted individuals (eg, dysphoria and cigarette smoking, and also socioeconomic status and general intellectual functioning). As these impairments were most accentuated in the CUDsubgroup, it may be speculated that the relatively better cognitive functioning in the CUD + subgroup reflects the mild cognitive improvement with active cocaine use (Johnson et al, 2005) that may potentially predispose to relapse. This speculation emphasizes the importance of developing or using a pharmacological agent that could improve neurocognitive function without negatively impacting mood thereby increasing positive outcome in treatment trials. Our results further indicate that determining urine status for drugs, a common practice in treatment settings, may provide an estimate of the cognitive and emotional impairments in cocaine abusers at time of treatment entry. This objective information may allow treatment providers to individually customize appropriate interventions.

\section{ACKNOWLEDGEMENTS}

This study was supported by grants from the National Institute on Drug Abuse (RZG: 1K23 DA15517-01, DA6278, DAO6891); NARSAD Young Investigator Award and Stony Brook/Brookhaven National Laboratory seed grant (RZG: 79/1025459); National Institute on Alcohol Abuse and Alcoholism (NDV: AA/ODO9481); Laboratory Directed Research and Development from US Department of Energy 
(OBER; DE-ACO2-98CH10886); and General Clinical Research Center (5-MO1-RR-10710).

\section{DISCLOSURE/CONFLICT OF INTEREST}

The authors of this paper declare that no financial support or compensation has been received from any individual or corporate entity for research or professional service, and there are no personal financial holdings that could be perceived as constituting a potential conflict of interest.

\section{REFERENCES}

Aharonovich E, Hasin DS, Brooks AC, Liu X, Bisaga A, Nunes EV (2006). Cognitive deficits predict low treatment retention in cocaine dependent patients. Drug Alcohol Depend 81: 313-322.

Aharonovich E, Nunes E, Hasin D (2003). Cognitive impairment, retention and abstinence among cocaine abusers in cognitivebehavioral treatment. Drug Alcohol Depend 71: 207-211.

Ardila A, Rosselli M, Strumwasser S (1991). Neuropsychological deficits in chronic cocaine abusers. Int J Neurosci 57: 73-79.

Association AP (2000). Diagnostic and Statistical Manual of Mental Disorders, 4th edn, text revision. American Psychiatric Association: Washington DC.

Bartzokis G, Lu PH, Beckson M, Rapoport R, Grant S, Wiseman EJ et al (2000). Abstinence from cocaine reduces high-risk responses on a gambling task. Neuropsychopharmacology 22: 102-103.

Beatty WW, Tivis R, Stott HD, Nixon SJ, Parsons OA (2000). Neuropsychological deficits in sober alcoholics: Influences of chronicity and recent alcohol consumption. Alcohol Clin Exp Res 24: 149-154.

Bechara A, Damasio AR, Damasio H, Anderson SW (1994). Insensitivity to future consequences following damage to human prefrontal cortex. Cognition 50: 7-15.

Bechara A, Dolan S, Denburg N, Hindes A, Anderson SW, Nathan PE (2001). Decision-making deficits, linked to a dysfunctional ventromedial prefrontal cortex, revealed in alcohol and stimulant abusers. Neuropsychologia 39: 376-389.

Beck AT, Steer RA, Brown GK (1996). Beck Depression Inventory Manual. The Psychological Corporation: San Antonio, TX.

Bell SL, Taylor RC, Singleton EG, Henningfield JE, Heishman SJ (1999). Smoking after nicotine deprivation enhances cognitive performance and decreases tobacco craving in drug abusers. Nicotine Tob Res 1: 45-52.

Benton A (1968). Differential behavioral effects in frontal lobe disease. Neuropsychologia 6: 53-60.

Benton A (1990). Facial recognition 1990. Cortex 26: 491-499.

Berg EA (1948). A simple objective treatment for measuring flexibility in thinking. J Gen Psychol 39: 15-22.

Berry J, van Gorp WG, Herzberg DS, Hinkin C, Boone K, Steinman L et al (1993). Neuropsychological deficits in abstinent cocaine abusers: Preliminary findings after two weeks of abstinence. Drug Alcohol Depend 32: 231-237.

Bolla K, Ernst M, Kiehl K, Mouratidis M, Eldreth D, Contoreggi C et al (2004). Prefrontal cortical dysfunction in abstinent cocaine abusers. J Neuropsychiatry Clin Neurosci 16: 456-464.

Bolla KI, Eldreth DA, London ED, Kiehl KA, Mouratidis M, Contoreggi C et al (2003). Orbitofrontal cortex dysfunction in abstinent cocaine abusers performing a decision-making task. Neuroimage 19: 1085-1094.

Budney AJ, Higgins ST, Hughes JR, Bickel WK (1993). Nicotine and caffeine use in cocaine-dependent individuals. J Subst Abuse 5: 117-130.

Clark L, Robbins TW, Ersche KD, Sahakian BJ (2006). Reflection impulsivity in current and former substance users. Biol Psychiatry 60: 515-522.
Delis D, Kaplan E, Kramer J, Ober B (2000). California Verbal Learning Test-II. The Psychological Corporation: San Antonio, TX. Di Sclafani V, Tolou-Shams M, Price LJ, Fein G (2002). Neuropsychological performance of individuals dependent on crack-cocaine, or crack-cocaine and alcohol, at 6 weeks and 6 months of abstinence. Drug Alcohol Depend 66: 161-171.

Diehl-Schmid J, Pohl C, Ruprecht C, Wagenpfeil S, Foerstl H, Kurz A (2007). The Ekman 60 faces test as a diagnostic instrument in frontotemporal dementia. Arch Clin Neuropsychol 22: 459-464.

Dudish-Poulsen S, Hatsukami DK (2000). Acute abstinence effects following smoked cocaine administration in humans. Exp Clin Psychopharmacol 8: 472-482.

Ekman P (1993). Facial expression and emotion. Am Psychol 48: 384-392.

Fan J, Fossella J, Sommer T, Wu Y, Posner MI (2003). Mapping the genetic variation of executive attention onto brain activity. Proc Natl Acad Sci USA 100: 7406-7411.

Fan J, Hof PR, Guise KG, Fossella J, Posner MI (2007). The functional integration of the anterior cingulate cortex during conflict processing. Cerebral Cortex print copy in press (originally published online July 2007, at www.cercor.oxford.org).

Fan J, McCandliss BD, Fossella J, Flombaum JI, Posner MI (2005). The activation of attentional networks. Neuroimage 26: 471-479.

Fan J, McCandliss BD, Sommer T, Raz A, Posner MI (2002). Testing the efficiency and independence of attentional networks. J Cogn Neurosci 14: 340-347.

Fossati P, Ergis AM, Allilaire JF (2002). [Executive functioning in unipolar depression: a review]. Encephale 28: 97-107.

Gerasimov MR, Franceschi M, Volkow ND, Rice O, Schiffer WK, Dewey SL (2000). Synergistic interactions between nicotine and cocaine or methylphenidate depend on the dose of dopamine transporter inhibitor. Synapse 38: 432-437.

Gillen RW, Kranzler HR, Bauer LO, Burleson JA, Samarel D, Morrison DJ (1998). Neuropsychologic findings in cocainedependent outpatients. Prog Neuropsychopharmacol Biol Psychiatry 22: 1061-1076.

Golden C (1978). Stroop Color and Word Test: a Manual for Clinical and Experimental Uses. Stoelting Company: Wood Dale, Illinois.

Goldstein RZ, Alia-Klein N, Tomasi D, Zhang L, Cottone LA, Maloney $\mathrm{T}$ et al (2007a). Is decreased prefrontal cortical sensitivity to monetary reward associated with impaired motivation and self-control in cocaine addiction? $A m J$ Psychiatry 164: 43-51.

Goldstein RZ, Leskovjan AC, Hoff AL, Hitzemann R, Bashan F, Khalsa SS et al (2004). Severity of neuropsychological impairment in cocaine and alcohol addiction: association with metabolism in the prefrontal cortex. Neuropsychologia 42: 1447-1458.

Goldstein RZ, Tomasi D, Alia-Klein N, Cottone LA, Zhang L, Telang $\mathrm{F}$ et al (2007b). Subjective sensitivity to monetary gradients is associated with frontolimbic activation to reward in cocaine abusers. Drug Alcohol Depend 87: 233-240.

Goldstein RZ, Volkow ND (2002). Drug addiction and its underlying neurobiological basis: Neuroimaging evidence for the involvement of the frontal cortex. Am J Psychiatry 159: 1642-1652.

Goldstein RZ, Woicik PA, Lukasik T, Maloney T, Volkow ND (2007c). Drug fluency: a potential marker for cocaine use disorders. Drug Alcohol Depend 89: 97-101.

Grant S, Contoreggi C, London ED (2000). Drug abusers show impaired performance in a laboratory test of decision making. Neuropsychologia 38: 1180-1187.

Heaton RK (1999). Wisconsin Card Sorting Test: Computer Version 3 for Windows, Research Edition Psychological Assessment Resource: Odessa, Florida. 
Heil SH, Badger GJ, Higgins ST (2001). Alcohol dependence among cocaine-dependent outpatients: demographics, drug use, treatment outcome and other characteristics. J Stud Alcohol 62: $14-22$.

Higgins ST, Bickel WK, Hughes JR, Lynn M, Capeless MA, Fenwick JW (1990). Effects of intranasal cocaine on human learning, performance, and physiology. Psychopharmacology (Berl) 102: 451-458.

Higgins ST, Budney AJ, Bickel WK, Foerg FE, Badger GJ (1994). Alcohol dependence and simultaneous cocaine and alcohol use in cocaine-dependent patients. J Addict Dis 13: 177-189.

Hoff AL, Riordan H, Morris L, Cestaro V, Wieneke M, Alpert R et al (1996). Effects of crack cocaine on neurocognitive function. Psychiatry Res 60: 167-176.

Homack S, Riccio CA (2004). A meta analysis of the sensitivity and specificity of the stroop color and word test with children. Arch Clin Neuropsychol 19: 725-743.

Hoshi R, Bisla J, Curran HV (2004). The acute and sub-acute effects of 'ecstasy' (mdma) on processing of facial expressions: preliminary findings. Drug Alcohol Depend 76: 297-304.

Ikeda H, Ikeda N, Miura H, Tominaga H, Yamada Y, Saito T (2003). Difference between alcohol dependence and nicotine dependence in cognitive dysfunction. Nihon Arukoru Yakubutsu Igakkai Zasshi 38: 512-518.

Jacobsen LK, Krystal JH, Mencl WE, Westerveld M, Frost SJ, Pugh KR (2005). Effects of smoking and smoking abstinence on cognition in adolescent tobacco smokers. Biol Psychiatry 57: $56-66$.

Johanson CE, Roehrs T, Schuh K, Warbasse L (1999). The effects of cocaine on mood and sleep in cocaine-dependent males. Exp Clin Psychopharmacol 7: 338-346.

Johnson B, Overton D, Wells L, Kenny P, Abramson D, Dhother S et al (1998). Effects of acute intravenous cocaine on cardiovascular function, human learning, and performance in cocaine addicts. Psychiatry Res 77: 35-42.

Johnson BA, Roache JD, Ait-Daoud N, Wallace CL, Wells LT, Wang $\mathrm{Y}$ et al (2005). Effects of isradipine on cocaineinduced changes in cognitive performance in recently abstinent cocaine-dependent individuals. Int J Neuropsychopharmacol 8: 549-556.

Jones CD, Bartee JA, Leite-Browning ML, Blackshear MA (2007). Methamphetamine-induced locomotor activity and behavioral sensitization: are dopamine $\mathrm{d} 3$ receptors involved? Cell Mol Biol (Noisy-le-grand) 53: 15-22.

Jovanovski D, Erb S, Zakzanis KK (2005). Neurocognitive deficits in cocaine users: a quantitative review of the evidence. J Clin Exp Neuropsychol 27: 189-204.

Kaufman JN, Ross TJ, Stein EA, Garavan H (2003). Cingulate hypoactivity in cocaine users during a go-nogo task as revealed by event-related functional magnetic resonance imaging. J Neurosci 23: 7839-7843.

Kemmis L, Hall JK, Kingston R, Morgan J (2007). Impaired fear recognition in regular recreational cocaine users. Psychopharmacology (Berl) 194: 151-159.

Kornreich C, Foisy ML, Philippot P, Dan B, Tecco J, Noel X et al (2003). Impaired emotional facial expression recognition in alcoholics, opiate dependence subjects, methadone maintained subjects and mixed alcohol-opiate antecedents subjects compared with normal controls. Psychiatry Res 119: 251-260.

Kumari V, Gray JA, Ffytche DH, Mitterschiffthaler MT, Das M, Zachariah E et al (2003). Cognitive effects of nicotine in humans: an fmri study. Neuroimage 19: 1002-1013.

Lezak MD (1995). Neuropsychological Assessment. Oxford University Press: New York.

Magura S, Rosenblum A (2000). Modulating effect of alcohol use on cocaine use. Addict Behav 25: 117-122.

Miller EK, Cohen JD (2001). An integrative theory of prefrontal cortex function. Annu Rev Neurosci 24: 167-202.
Muller CP, Carey RJ, Huston JP (2003). Serotonin as an important mediator of cocaine's behavioral effects. Drugs Today (Barc) 39: 497-511.

Muller CP, Carey RJ, Huston JP, De Souza Silva MA (2007). Serotonin and psychostimulant addiction: focus on 5-htlareceptors. Prog Neurobiol 81: 133-178.

Neuhaus AH, Koehler S, Opgen-Rhein C, Urbanek C, Hahn E, Dettling M (2007). Selective anterior cingulate cortex deficit during conflict solution in schizophrenia: an event-related potential study. J Psychiatr Res 41: 635-644.

O’Donnel WE, De Soto CB, Reynolds DM (1984). Sensitivity and specificity of the neuropsychological impairment scale (NIS). J Clin Psychol 4: 553-555.

O'Malley S, Adamse M, Heaton RK, Gawin FH (1992). Neuropsychological impairment in chronic cocaine abusers. Am J Drug Alcohol Abuse 18: 131-144.

Pace-Schott EF, Stickgold R, Muzur A, Wigren PE, Ward AS, Hart CL et al (2005). Sleep quality deteriorates over a bingeabstinence cycle in chronic smoked cocaine users. Psychopharmacology (Berl) 179: 873-883.

Parsons OA, Nixon SJ (1993). Neurobehavioral sequelae of alcoholism. Neurol Clin 11: 205-218.

Pich EM, Pagliusi SR, Tessari M, Talabot-Ayer D, Hooft van Huijsduijnen R, Chiamulera C (1997). Common neural substrates for the addictive properties of nicotine and cocaine. Science 275: 83-86.

Poling J, Kosten TR, Sofuoglu M (2007). Treatment outcome predictors for cocaine dependence. Am J Drug Alcohol Abuse 33: 191-206.

Reitan R (1985). The Halstead-Reitan Neuropsychological Test Battery. Neuropsychology Press: Tuscon, AZ.

Reitan RM (1955). The relation of the trail making test to organic brain damage. J Consult Psychol 19: 393-394.

Richter KP, Ahluwalia HK, Mosier MC, Nazir N, Ahluwalia JS (2002). A population-based study of cigarette smoking among illicit drug users in the United States. Addiction 97: 861-869.

Robertson KR, Parsons TD, Sidtis JJ, Hanlon Inman T, Robertson WT, Hall CD et al (2006). Timed gait test: normative data for the assessment of the aids dementia complex. J Clin Exp Neuropsychol 28: 1053-1064.

Rogers RD, Robbins TW (2001). Investigating the neurocognitive deficits associated with chronic drug misuse. Curr Opin Neurobiol 11: 250-257.

Roll JM, Higgins ST, Budney AJ, Bickel WK, Badger GJ (1996). A comparison of cocaine-dependent cigarette smokers and nonsmokers on demographic, drug use and other characteristics. Drug Alcohol Depend 40: 195-201.

Ruff RM, Parker SB (1993). Gender- and age-specific changes in motor speed and eye-hand coordination in adults: normative values for the finger tapping and grooved pegboard tests. Percept Mot Skills 76: 1219-1230.

Rusted J, Graupner L, O'Connell N, Nicholls C (1994). Does nicotine improve cognitive function? Psychopharmacology (Berl) 115: $547-549$

Rusted J, Graupner L, Warburton D (1995). Effects of post-trial administration of nicotine on human memory: evaluating the conditions for improving memory. Psychopharmacology (Berl) 119: 405-413.

Schuckit MA, Daeppen JB, Danko GP, Tripp ML, Smith TL, Li TK et al (1999). Clinical implications for four drugs of the dsm-iv distinction between substance dependence with and without a physiological component. Am J Psychiatry 156: 41-49.

Sinha R, Li CS (2007). Imaging stress- and cue-induced drug and alcohol craving: association with relapse and clinical implications. Drug Alcohol Rev 26: 25-31.

Smith A (1982). Symbol Digit Modality Test (SDMT) Manual. Western Psychological Services: Los Angeles. 
Sofuoglu M, Dudish-Poulsen S, Brown SB, Hatsukami DK (2003). Association of cocaine withdrawal symptoms with more severe dependence and enhanced subjective response to cocaine. Drug Alcohol Depend 69: 273-282.

Strauss E, Sherman EM, Spreen O (2006). A Compendium of Neuropsychological Tests: Administration, Norms, and Commentary. Oxford University Press: New York.

Tabachnick BG, Fidel LS (1983). Using Multivariate Statistics. Harper and Row: New York.

Thompson AM, Swant J, Gosnell BA, Wagner JJ (2004). Modulation of long-term potentiation in the rat hippocampus following cocaine self-administration. Neuroscience 127: 177-185.

Tomasi D, Goldstein RZ, Telang F, Maloney T, Alia-Klein N, Caparelli EC et al (2007a). Thalamo-cortical dysfunction in cocaine abusers: implications in attention and perception. Psychiatry Res 155: 189-201.

Tomasi D, Goldstein RZ, Telang F, Maloney T, Alia-Klein N, Caparelli EC et al (2007b). Widespread disruption in brain activation patterns to a working memory task during cocaine abstinence. Brain Res 1171: 83-92.

Townshend JM, Duka T (2003). Mixed emotions: alcoholics' impairments in the recognition of specific emotional facial expressions. Neuropsychologia 41: 773-782.

Verdejo-Garcia A, Rivas-Perez C, Vilar-Lopez R, Perez-Garcia M (2007). Strategic self-regulation, decision-making and emotion processing in poly-substance abusers in their first year of abstinence. Drug Alcohol Depend 86: 139-146.

Volkow ND, Chang L, Wang GJ, Fowler JS, Leonido-Yee M, Franceschi D et al (2001). Association of dopamine transporter reduction with psychomotor impairment in methamphetamine abusers. Am J Psychiatry 158: 377-382.

Wang G, Volkow ND, Logan N, Pappas C, Wong W, Zhu N et al (2001). Brain dopamine and obesity. Lancet 357: 354-357.

Wang GJ, Telang F, Jayne M, Ma J, Rao M (2004). Exposure to appetitive stimuli markedly activates the human brain. Neuroimage 21: 1790-1797.

Wang K, Fan J, Dong Y, Wang CQ, Lee TM, Posner MI (2005). Selective impairment of attentional networks of orienting and executive control in schizophrenia. Schizophr Res 78: 235-241.

Warburton DM, Skinner A, Martin CD (2001). Improved incidental memory with nicotine after semantic processing, but not after phonological processing. Psychopharmacology (Berl) 153: 258-263.

Wechsler D (1987). Wechsler Memory Scale Manual. The Psychological Corporation: San Antonio, TX.

Wechsler D (1997). Wechsler Adult Intelligence Scale, 3rd edn Psychological Corporation: San Antonio, TX.

Wilkinson G (1993). The Wide-Range Achievement Test 3-Administration Manual. Wide Range Inc.: Wilmington, DE.

Supplementary Information accompanies the paper on the Neuropsychopharmacology website (http://www.nature.com/npp) 